\title{
Integrated embedding optimization applied to Salt Lake valley aquifers
}

\author{
A. Gharbi \\ Esier Medjez el Bab, Medjez el Bab, Tunisia

\section{R. C. Peralta} \\ Biological and Irrigation Engineering Department, Utah State University, Logan
}

\begin{abstract}
The embedding optimization modeling approach is adapted to aid sustainable groundwater quantity and quality management of complex nonlinear multilayer aquifers. Implicit block-centered finite difference approximations of the quasi three-dimensional unsteady flow equation and Galerkin finite element approximations of the two-dimensional advection-dispersion transport equation are embedded directly as constraints in the model. Also used are nonlinear constraints describing river-aquifer interflow, evapotranspiration, and vertical flow reduction due to unconfinement. These circumvent use of large numbers of integer variables. The use of both linear and nonlinear formulations in a cyclical manner reduces execution time and improves confidence in solution optimality. The methodology is demonstrated for Salt Lake valley where groundwater quantity and quality management are needed, the proportion of pumping cells and cells needing head constraint is large, and many flows are described by discrete nonlinear or piecewise linear functions.
\end{abstract}

\section{Introduction}

Many computer models have been developed for optimizing groundwater management. These have been developed for a wide range of problems and specific purposes. This paper describes a model applicable for aiding sustained groundwater yield planning and achieving future groundwater quality goals in a system where many cells must contain unsteady pumping as a decision variable or head as a bounded state variable. Included are many constraints describing (1) flow processes that are piecewise linear and (2) transport of dispersed (such as nonpoint source) groundwater contamination. Cited below are relatively recent pertinent studies on optimizing management of groundwater flow (especially in nonlinear systems) or contaminant transport. Comprehensive reviews of earlier models that combine simulation and optimization capability (hereinafter referred to as s/o models) are given by Gorelick [1983] and Willis and Yeh [1987].

Within s/o models, hydraulic head response to pumping and stimuli has generally been represented using either embedding or response matrix (RM) methods. In the embedding approach, numerical approximations of the flow equation are included directly as constraints. The RM approach involves more stages. First, a simulation model is used to compute system response to unit pumping rates (linear system responses to these rates have been termed influence coefficients, discrete kernels, algebraic technological functions, and other variants). Second, the $s / 0$ model is used to compute optimal pumping strategies. The s/o model uses influence coefficients and superposition to describe system response at specified locations due to pumping. The array of Copyright 1994 by the American Geophysical Union.

Paper number 93 WR03349.

0043-1397/94/93WR-03349\$05.00 influence coefficients used in the superposition equations is termed a response matrix.

Embedding models have also been used successfully for transient problems [Yazicigil and Rasheeduddin, 1987; Willis et al, 1989]. However, embedding models can be unnecessarily large for some situations because they must contain one flow equation per cell per stress period.

The s/o models have been most commonly applied to optimize flow within linear (confined) aquifers or aquifers that can be considered linear (having sufficient saturated thickness that changes therein do not significantly affect computed heads). When applied to nonlinear systems, most s/o models have assumed that at least some nonlinear aspects can be treated linearly [e.g., Heidari, 1983; Danskin and Gorelick, 1985; Peralta and Killian, 1985; Willis and Finney, 1985; Jones et al., 1987; Lall and Santini, 1989; Willis and Jones, 1987; Willis and Yeh, 1987].

Cycling is one approach for addressing nonlinear problems linearly. Here cycling refers to the process of assuming parameter values, computing an optimal strategy, checking the validity of the initially assumed parameters, and beginning the process anew (if necessary). Cycling has been often used to permit treating unconfined aquifers linearly.

Danskin and Gorelick [1985] used mixed integer programming to address river-aquifer interflow. Relatively few integer variables were required, partly because single piecewise expressions represented entire groups of cells, and it was probably assumed that optimal groundwater pumping adjacent to the river would not affect the piecewise interflow expressions. Reichard [1987] used more integer variables while assuming that only saturated river-aquifer interflow existed.

Both RM and embedding methods have also been applied to manage groundwater contamination. In overview, optimal groundwater contaminarit control has been performed using 
linear programming (many examples including Molz and Bell [1977]), quadratic programming (many examples including Lefkoff and Gorelick [1986] and Peralta and Ward [1991]), nonlinear programming [Willis, 1979; Gorelick et al., 1984; Ahlfeld et al., 1986, 1988a, b; Wagner and Gorelick, 1987], forms of dynamic programming [Chang, 1990; Andricevic and Kitanidis, 1990; Lee and Kitanidis, 1991; Culver and Shoemaker, 1992], and simulated annealing [Dougherty and Marryott, 1991].

In linear and some nonlinear s/o models, contaminant migration has been controlled primarily by controlling potentiometric heads or gradients, or groundwater or contaminant velocities [e.g., Molz and Bell, 1977; Colarullo et al., 1984; Atwood and Gorelick, 1985; Lefkoff and Gorelick, 1986; Peralta and Ward, 1991].

In other models, migration has been more explicitly controlled [Alley, 1986; Datta and Peralta, 1986b; Solaimanian, 1989; Lefkoff and Gorelick, 1990; Dougherty and Marryott, 1991]. A representative goal has been to impose constraints on the concentrations that will exist at control locations at prespecified points in time. Cited approaches to constrain future concentrations differ and apply to differing conditions. One of the most complicated nonlinear two-dimensional transport problems is the one addressed herein, optimizing unsteady extraction of contaminated water from many wells to achieve target concentrations all around the pumping wells, when concentrations are functions of initially unknown flow fields resulting from the pumping rates being optimized. This paper differs from previous works in the degree or manner in which this is achieved.

Willis [1979] used the embedding technique to develop a model to manage groundwater quality. He used the Galerkin finite element method to approximate both flow and transport equations. The model was then decomposed into two independent subproblems and solved using linear programming.

Gorelick et al. [1984] presented a methodology to address the nonlinearity in the flow and transport equations when the response matrix is used. They used a simulation saturated unsaturated transport (SUTRA) model [Voss, 1984] to compute the Jacobian of the nonlinear constraints (transport equation) with respect to each decision variable (pumping or injection) after each iteration. This Jacobian and other constraints are used as linear constraints for a subsequent optimization model.

Ahlfeld et al. [1986] tested the same procedure on a hypothetical system of 100 nodes. They concluded that computational costs are dominated by the repeated simulations required to compute the Jacobian and that this characteristic limits the use of this methodology to problems with few decision variables. To avoid the repeated computation of the Jacobian matrices after each iteration, Ahlfeld [1990] used sensitivity theory to derive a general relationship for computing each element of the Jacobian. Wanakule et al. [1986] followed the same general approach as Gorelick et al. [1984] but used an analytical method to develop the Jacobian for purely volumetric optimization.

Dougherty and Marryott [1991] applied the simulated annealing methodology to groundwater management. They concluded that further testing and improvements can be expected. Culver and Shoemaker [1992] used the successive approximation linear quadratic regulator (SALQR) method for groundwater remediation. They used different time steps for both the optimization model and the numerical groundwater model.

These recent papers did not attempt to improve application of the embedding approach to solute transport management. The lack of interest in this goal is probably the result of two factors. First, the embedding method is appropriate for only a small subset of management problems [Peralta and Killian, 1987; Peralta and Datta, 1990; Datta and Peralta, 1986a]. Second, some previous researchers antici. pated or reported difficulties in applying the embedding approach, especially for transient flow conditions [Gorelick, 1983; Tung and Kolterman, 1985; Yazdanian and Peralta, 1986]. Utilized optimization algorithms sometimes had diffculties with lower-upper basis factorization when banded matrices were involved (such matrices always exist in embedding models). The result was numerical instability.

This paper shows a way of considering solute transport in addressing problems for which the embedding method is desirable. It presents a procedure that overcomes difficulties previously associated with using the embedding method. It shows an integrated way of implementing the embedding method for optimizing pumping and groundwater quality management in complex aquifer systems having unsteady pumping and transient nonlinear flow and transport. To aid implementation, the method is contained within an interactive program. Included contributions are both linear and nonlinear version of the flow and transport optimization model and, as is described later, partitioned and combined forms of the flow equation for both linear and nonlinear models. The presented linear cyclical differencing approach permits optimizing unsteady pumping, while extracting contaminated water from cells at which pumping, concentration, and head are simultaneous unknowns.

The presented method is useful for large-scale, long-term reconnaissance level planning. It is also suitable for situations in which the embedding method is commonly preferred, systems in which a large proportion of the cells have pumping decision variables and require head constraints [Peralta et al., 1991]. It is also appropriate for reconnaissance planning if a large proportion of the cells have piecewise variable-head dependent functions to describe flow processes. This is a common feature of areas having wetlands and drained and irrigated agriculture. There, evapotranspiration $(E t)$ and flow from drains vie with pumping from wells as significant groundwater discharges.

\section{Term Definitions}

\subsection{Accessed Algorithms}

Modular in-core nonlinear optimization system (MINOS) [Murtagh and Saunders, 1987] is a large-scale optimization system for solving sparse linear and nonlinear problems. It solves linear problems using a modified primal simplex approach. When nonlinearities are only in the objective function, MINOS uses a reduced-gradient algorithm with a quasi-Newton algorithm. It addresses nonlinear constraints using a projected augmented Lagrangian algorithm. It attacks lower-upper (LU) factorization of the basis matrix using a Markowitz ordering scheme and Bartels-Golub updates. This feature especially helps with addressing the sparse, highly ordered matrices typical of embedding models.

The Generalized algebraic modeling system (GAMS) 
[Brooke et al., 1988] simplifies use of several optimization algorithms, including MINOS. GAMS is a high-level language which integrates use of relational databases and mathematical programming. It includes the discrete nonlinear programming (DNLP) option. DNLP addresses problems containing nonsmooth functions. As will be seen later, it permits use of maximum, minimum, or absolute value declarations within equations.

\subsection{Iteration and Cycle}

The term iteration refers to processing within the MINOS solver. All equations composing the optimization model are solved during a particular iteration. Many iterations are usually required before MINOS halts computation and declares that an optimal solution is found. However, when addressing a nonlinear problem using a linear surrogate, that optimal solution might not be the best stopping point. Thus, after reinitialization, another optimization (cycle) might be performed. Many cycles might be needed before a satisfactory optimal solution is found. The general procedure is as follows: (1) A cycle for addressing an unconfined aquifer begins when assumed values (such as heads) are read. (2) Some parameters (such as transmissivities and dispersivities) are then computed and automatically placed within the optimization model constraint equations. (3) Optimization begins and iterations are performed until an optimal solution is determined. (4) Then optimal strategy results (fluxes and heads) are compared with the values assumed in step 1 . If the differences are acceptably small, the process halts. Otherwise, optimal strategy results are used in step 1, and a new cycle commences. Multiple cycles are usually needed to reach a satisfactory (converged) optimal solution for unconfined aquifers or systems having piecewise functions.

\section{Model Formulation}

\subsection{Objective Function}

The multiple objectives used in this model involve maximizing $Z$, the total groundwater extraction, while minimizing the excessive groundwater contaminant concentrations during a planning period of $K$ time steps. In a system of $M$ total cells, $\Omega$ are cells where pumping is optimized, and $N Q$ are nodes where water quality is to be controlled. This objective function uses the weighting approach to address noncommensurate multiple objectives.

$$
\max Z=\sum_{k=1}^{K} \sum_{\omega=1}^{\Omega} g_{\omega, k}-w c \sum_{k q=1}^{K Q} \sum_{n q=1}^{N Q} C_{n q, k q}^{+}
$$

where $g_{\omega, k}$ is spatially distributed pumping (positive for extraction) from cell $\omega$ during stress period $k ; \Omega$ is the total number of possible pumping cells in the study area; $N Q$ is the total number of nodes where water quality control is required; $w c$ is the weighting factor associated with quality control (when $w c$ is equal to 0 , the mono-objective is to maximize pumping; a large value of $w c$ will force $c_{n q, k q}^{+}$to be smaller); $k q$ is the time step used for water quality simulation (we use several smaller time steps for water quality simulation within one stress period used for flow simulation); and $c_{n q, k q}^{+}$is the concentration in excess of the target concentration desired for node $n q$ by the end of time step $k q$. Pumping $g_{\omega, k}$ in studies such as this usually represents the total pumping of many individual wells within a cell.

\subsection{Constraints}

3.2.1. Finite difference approximation of the flow equation. The optimization model contains as constraints an implicit quasi three-dimensional finite difference approximation of the flow equation as described by McDonald and Harbaugh [1988]. (Their modular three-dimensional groundwater flow (MODFLOW) model is very widely used.) The right-hand side of the flow equation can be represented by

$$
\begin{aligned}
\frac{S_{\bar{o}} \Delta x_{j} \Delta y_{i}}{\Delta t_{k}}\left(h_{\bar{\delta}, k}\right. & \left.-h_{\bar{\delta}, k-1}\right)+q_{\bar{o}, k}^{b}+g_{\bar{o}, k}+q_{\bar{o}, k}^{t}+q_{\bar{o}, k}^{z}+q_{\bar{o}, k}^{s} \\
& +q_{\bar{\delta}, k}^{c}+q_{\bar{o}, k}^{p} \quad \text { for } \bar{o} \in M, k \in K
\end{aligned}
$$

where $\bar{o}$ is the number of a particular cell $(i, j, l)$ located in row $i$, column $j$, and layer $l ; S_{\delta}$ is the storage coefficient or specific yield for cell $i, j, l ; \Delta x_{j}, \Delta y_{i}$ is the cell size in $x$ and $y$ directions of cell $\bar{\delta} ; \Delta t_{k}$ is the duration of time step $k ; h_{\delta, k}$ is the average potentiometric head in cell $\bar{\sigma}$ at end of stress period $k ; q_{\bar{b}, k}^{b}$ are the flows across aquifer boundaries that are unaffected by management (i.e., bedrock recharge or deep percolation); $q_{\overline{0}, k}^{t}$ is the distributed evapotranspiration (positive) from the aquifer; $q_{\tilde{\delta}, k}^{z}$ is the lateral flow across a boundary (which depends on the boundary's fixed head and adjacent heads); $q_{\delta, k}^{s}$ is the flow between the aquifer and streams; $q_{\bar{o}, k}^{c}$ is the saturated flow between the aquifer and general head boundary cells; and $q_{o}^{p}, k$ is the reduction in vertical flow between cells in layer $l$ and the lower layer $l+$ 1 due to a drop in head below the top of layer $l+1$. Of the flows all except $q^{b}$ are determined via optimization.

3.2.2. The two-dimensional Galerkin finite element approximation of the unsteady state solute transport. The basic form of the finite element transport equation embedded as constraints in the optimization model is similar to that outlined by Huyakorn et al. [1986] for simulation, except that the consistent formulation is used instead of the lumped form when approximating the time dependent term in the transport equation [Voss, 1984].

The nonlinear formulation of the transport equation is

$$
\left(A_{n m}+\frac{D_{n m}}{\Delta t_{k q}}\right) c_{m, k q+1}=\frac{D_{n m}}{\Delta t_{k q}} c_{m, k q}+B_{n}
$$

where $n$ and $m$ are the designators identifying individual nodes from among the $N$ total finite element nodes where concentrations are to be computed; $\Delta t_{k q}$ is the duration of the time step $k q$, a fraction of $\Delta t_{k}$; and $A_{n m}$ and $D_{n m}$ are functions of the velocity, dispersion, and dimensions of the element [Huyakorn et al., 1986].

Equation (3) contains products of velocity, concentration, source or sink terms, and dispersivities. These constitute nonlinearities in the transport equation, since they are functions of initially unknown pumping, heads, and concentrations and are part of the solution. Within the optimization model it is desirable to have a linear means of expressing the transport process, even if pumping and flow fields are initially unknown. Here this is done by separating the advection and dispersion processes and treating them as described below.

To linearly describe advective transport, the products of velocity, source or sink terms, and concentrations are replaced by the following: 


$$
\begin{aligned}
& V c=V_{p} c+V c_{p}-V_{p} c_{p} \\
& Q c=Q_{p} c+V c_{p}-Q_{p} c_{p}
\end{aligned}
$$

where $V_{p}, Q_{p}$, and $c_{p}$ are the velocity, source or sink term, and concentration, respectively, from the previous cycle. Since values from a previous cycle are known in a subsequent cycle, each term in (4) has only one unknown, and the equation is linear. Note that both velocities and concentrations from both current and previous cycles are used. This speeds convergence.

Dispersivities are computed using known velocities from the previous cycle. Using (4) while cycling and using known velocities for dispersion greatly speed the process of converging to optimal solutions. Because of the linearization and partitioning of the advection-dispersion, this process could be termed cyclical linear differencing. Heads used to compute velocities and flow rates are from the finite difference approximation shown in (2). Pumping, heads, velocities, and concentrations are all computed simultaneously.

3.2.3. Overachievement and underachievement values for concentrations. This constraint is intended to describe the computed concentration at a node with respect to a known reference concentration (target concentration).

$$
\begin{gathered}
c_{n q, k q}=c_{n q, k q}^{\text {target }}+c_{n q, k q}^{+}-c_{n q, k q}^{-} \\
c_{n q, k q}^{\text {target }}, c_{n q, k q}^{-}, c_{n q, k q}^{+} \geq 0
\end{gathered}
$$

where $c_{n q}^{\text {target }}$ is the target concentration at node $n q$ by the end of time step $k q ; c_{n q, k q}^{+}$is the amount by which the concentration simulated for node $n q$ by the end of time step $k q$ exceeds the target concentration; and $c_{n q, k q}$ is the amount by which the optimal concentration is below the target concentration in node $n q$ by the end of time step $k q$.

3.2.4. Expressions describing piecewise linear or nonlinear flows. The Utah State University Embedding Model (USUEM) includes embedded forms of all (2) flows. Only those expressed both piecewise-linearly and nonlinearly are described below. Included are evapotranspiration, riveraquifer interflow, and vertical flow reduction. We developed nonlinear forms, instead of using a mixed integer approach, because (1) conventional wisdom is that having large numbers of integer variables within a model can cause unexpected and painful difficulties, (2) experience had shown that the DNLP option of GAMS/MINOS successfully addressed piecewise constraints of this type, and (3) there was no commercially available mixed integer optimization algorithm that could also handle nonlinear constraints of the type we expected with solute transport management. Using mixed integer programming for these flows in our embedding model would have required over 1000 integer variables. (This partly results from having to model each cell separately for each stress period.) The exact number is uncertain since it is difficult to anticipate (and one does not wish to predetermine) where changes from confined to unconfined conditions or saturated to unsaturated flow might occur.

In USUEM, linear and nonlinear forms are not used simultaneously. They are used in the linear and nonlinear models, respectively. For illustration, below are described both the piecewise linear constraints and the surrogate nonlinear constraint describing evapotranspiration. Three expressions are used to describe evapotranspiration response to water table head. A difficulty with using those constraints directly lies in the need to decide before optimization which linear segment to apply for each cell. If using just linear programming and cycling, one would pick the segment appropriate for the optimal head computed for that cell in the previous cycle. Unfortunately, segment preselection can cause fluxes and heads to change, causing the selected segment to differ from cycle to cycle. This flipflopping can make convergence difficult. Using mixed integer programming would require at least two integer variables per evapotranspiration cell, per stress period. An alternative is to use the nonlinear form of the constraint.

The piecewise linear evapotranspiration constraint is

$$
\begin{array}{ll}
q_{\bar{\delta}, k}^{t}=E_{\bar{o}} \Delta x_{j} \Delta y_{i} & \text { for } h s_{\bar{o}}<h_{\bar{o}, k} \\
q_{\bar{\sigma}, k}^{t}=E_{\bar{o}} \Delta x_{j} \Delta y_{i} \frac{\left[h_{\bar{o}, k}-\left(h s_{\bar{o}}-d s_{\bar{o}}\right)\right]}{d s_{\bar{o}}} & \text { for } h s_{\bar{o}}-d s_{\bar{o}}<h_{\bar{o}, k} \leq h s_{\bar{\sigma}} \\
q_{\bar{o}, k}^{t}=0 & \text { for } h_{\bar{\sigma}, k} \leq h s_{\bar{o}}-d s_{\bar{o}}
\end{array}
$$

The alternative nonlinear evapotranspiration constraint is

$q_{\bar{\delta}, k}^{t}=\frac{E_{\bar{o}} \Delta x_{j} \Delta y_{i}}{d s_{\bar{\delta}}}\left[\min \left(h s_{\bar{o}}, h_{\bar{\delta}, k}\right)-\min \left(h s_{\bar{o}}-d s_{\bar{o}}, h_{\bar{\delta}, k}\right)\right]$

where $E_{\bar{o}}$ is the potential evapotranspiration in cell $\bar{o} ; h s_{\delta}$ is the potentiometric surface elevation below which the evapotranspiration rate begins to decrease; $d s_{\bar{\sigma}}$ is the extinction depth in cell $\bar{o}$ (depth below $h s_{\bar{o}}$ at which there is no evapotranspiration); and $\min (r, s)$ is a function which equals the lesser value of the expressions $r$ and $s$.

The nonlinear constraints described here and below are important for model performance because the potential errors caused by equation preselection can be significant in some situations. Such errors can result with other fluxes in addition to Et; for example, river-aquifer interflow, vertical aquifer interflow, and flow from drains. Such fluxes can account for half or more of the discharge from some systems.

USUEM has embedded linear river-aquifer interflow constraints. It also has the following nonlinear constraint, which is appropriate to define both unsaturated or saturated interflow:

$$
q_{\bar{\delta}, k}^{s}=\Gamma_{\bar{o}} \max \left(h_{\bar{\delta}, k}-\sigma_{\bar{o}, k}, B_{\bar{o}}-\sigma_{\bar{\delta}, k}\right)
$$

where $\Gamma_{\bar{o}}$ is the hydraulic conductance of the river-aquifer interconnection (including any clogging layer); $\sigma_{\bar{o}, k}$ is the elevation of the free water surface in the river; $B_{\bar{o}}$ is the bottom of the river in cell $\bar{o}$; and $\max (r, s)$ equals the greater of the numerical values of the expressions for $r$ and $s$.

MODFLOW uses two linear equations to describe the reduction in vertical flow between aquifer layers that results when a portion of a confined aquifer becomes unconfined and unsaturated. This frequently occurs when pumping causes the piezometric surface to drop below the top of an aquifer layer. USUEM includes the same piecewise linear expressions, as well as the following nonlinear surrogate:

$$
q_{o, k}^{p}=c v_{i, j, l} \min \left(h_{i, j, l+1, k}-\operatorname{Top}_{i, j, l+1}, 0\right)
$$

where $c v_{i, j, l}$ is the vertical conductance; and Top $\operatorname{Top}_{i, j, l+1}$ is the top of aquifer layer $l+1$ in cell $i, j, l+1$. 
3.2.5. Other constraints and bounds. Equation (10) insures that pumping increases monotonically (i.e., increases or remains the same but never decreases). It also assures that the computed optimal pumping is sustainable.

$$
g_{\bar{\delta}, k-1} \leq g_{\bar{\delta}, k} \leq g_{\delta}^{s s}
$$

where $g_{\vec{o}}^{s s}$ is an initially unknown steady groundwater pumping beyond the planning period. It is determined by the model during optimization using a set of steady state flow constraints, which are solved simultaneously with the transient flow constraints of (2). Knapp and Fienerman [1985] give a good rationale for the importance of sustained yield groundwater planning.

Other bounds are intended to enforce natural conditions, legal rights, or management goals. Lower and upper bounds are placed on pumping, heads, and recharge at all individual cells (this does not affect the number of equations in the model); on flow across the entire set of constant head cells; and on river-aquifer interflow occurring within specified groups of river cells.

\section{Integrated Approach Solution Technique: Switching Between Linear Versus Nonlinear and Partitioned Versus Combined Options}

The USUEM user can formulate the management problem utilizing either combined or partitioned versions of linear or nonlinear constraint equations. Reasons for having these options are explained below. Also, the user can apply either the linear or the nonlinear model in any cycle. The ability to switch from one to the other can be useful and necessary if one of the options is experiencing numerical difficulties. The switching ability is an important feature of the integrated embedding modeling approach.

\subsection{Linear Versus Nonlinear Options}

Good reasons for using the linear model to solve groundwater management problems include solution speed and global optimality of solutions. A linear model is easier to solve and generally solves more rapidly than a nonlinear model. We obtained essentially the same results from both models. Our comparisons involved several test cases and a range of initial guesses of optimal solutions for both models.

In some situations it is better to use the nonlinear instead of the linear form. In an initial optimization for a complicated physical system, if the initial guess (of the optimal solution) is not close to the optimal solution, a linear solver might declare the problem to be infeasible, even though a solution might exist. This occurs because in the linear programming (LP) formulation the equations describing Et, river and drain-aquifer interflow, and flow reduction are based on assumed heads. Even if those heads are the result of simulation by a reputable model (i.e., MODFLOW), computational tolerances can cause the redefined equations to be infeasible. In other words, preselection of linear equation segments excessively limits MINOS' freedom. This restriction can lead to an infeasible solution even though the problem could be optimized if the DNLP option were used.

The DNLP formulation can help because therein Et, river and drain-aquifer interflow, and flow reduction are described by equations which are more realistic for the heads and pumping values being optimized. These fluxes are varied and adjusted within the model to get an optimal solution. In this study some scenarios were run using both formulations. When infeasibilities were obtained using the LP formulation, the DNLP model was successful. Developing good initial guesses of the solution is important.

Once a feasible solution is obtained, the linear formulation usually converges more rapidly than the nonlinear model. In addition, it is easier to solve slightly modified versions of the original problem. Solution time is dependent on the initial guess.

The LP model is useful for its ability to compute globally optimal solutions. The optimal solution to a linear problem is always globally optimal. However, it is difficult to prove that the optimal solution to a linear surrogate of a nonlinear problem is globally optimal. Similarly, it is not theoretically easy to prove that the solutions computed by the DNLP model are globally optimal, especially in the presence of different processes that can be described by concave and convex functions according to parameters that might change from one cycle to another. However, it is possible to get a feeling of proximity to global optimality of a nonlinearly optimal solution by running the LP model using results from the nonlinear formulation. Our experience has been that both LP and DNLP models developed by USUEM ultimately compute almost the same optimal strategies. This has involved several test cases and a wide range of different initial guesses (of the optimal strategy) for both models.

\subsection{Partitioned Versus Combined Options}

Another desirable feature is having both partitioned and combined forms of the flow equation. In the partitioned form, each flux that can be described by piecewise function is represented by a separate variable and equation (or set of equations). In the combined approach there is only one flow equation per cell and only heads and pumping are variables. The partitioned form is more useful in the initial stages of optimization for identifying processes and data that cause constraint violations. The combined form is more useful later because it requires less memory and solves more rapidly.

\section{Application Background: The Aquifer System and Management Problems}

Salt Lake valley lies within the most populated county in the state of Utah. It covers an area of about 500 square miles $\left(1400 \mathrm{~km}^{2}\right.$ ). The groundwater reservoir (discretized in Figure 1) consists of two unconsolidated aquifer layers of Quaternary age. Sources of recharge include bedrock recharge, seepage from irrigation, precipitation, canals, and creek channels [Hely et al., 1971]. Also, some recharge to the shallow aquifer comes from the upward movement of water from the confined aquifer. Discharges result from pumping, flowing wells, evapotranspiration, seeps, springs, and subsurface flow to the Great Salt Lake and sections of Jordan River and its tributaries. The number of wells in the valley is estimated to be more than 12,000. Major groundwater uses are for municipalities, industries, private residences, irrigation, and livestock. Almost all pumping is from the lower layer, which has better water quality than the upper layer. Current approved groundwater rights have been thought to exceed what the aquifer can satisfactorily provide (D. Hansen et al., personal communication, 1989, 1990). Requests for groundwater are expected to increase [Bishop 


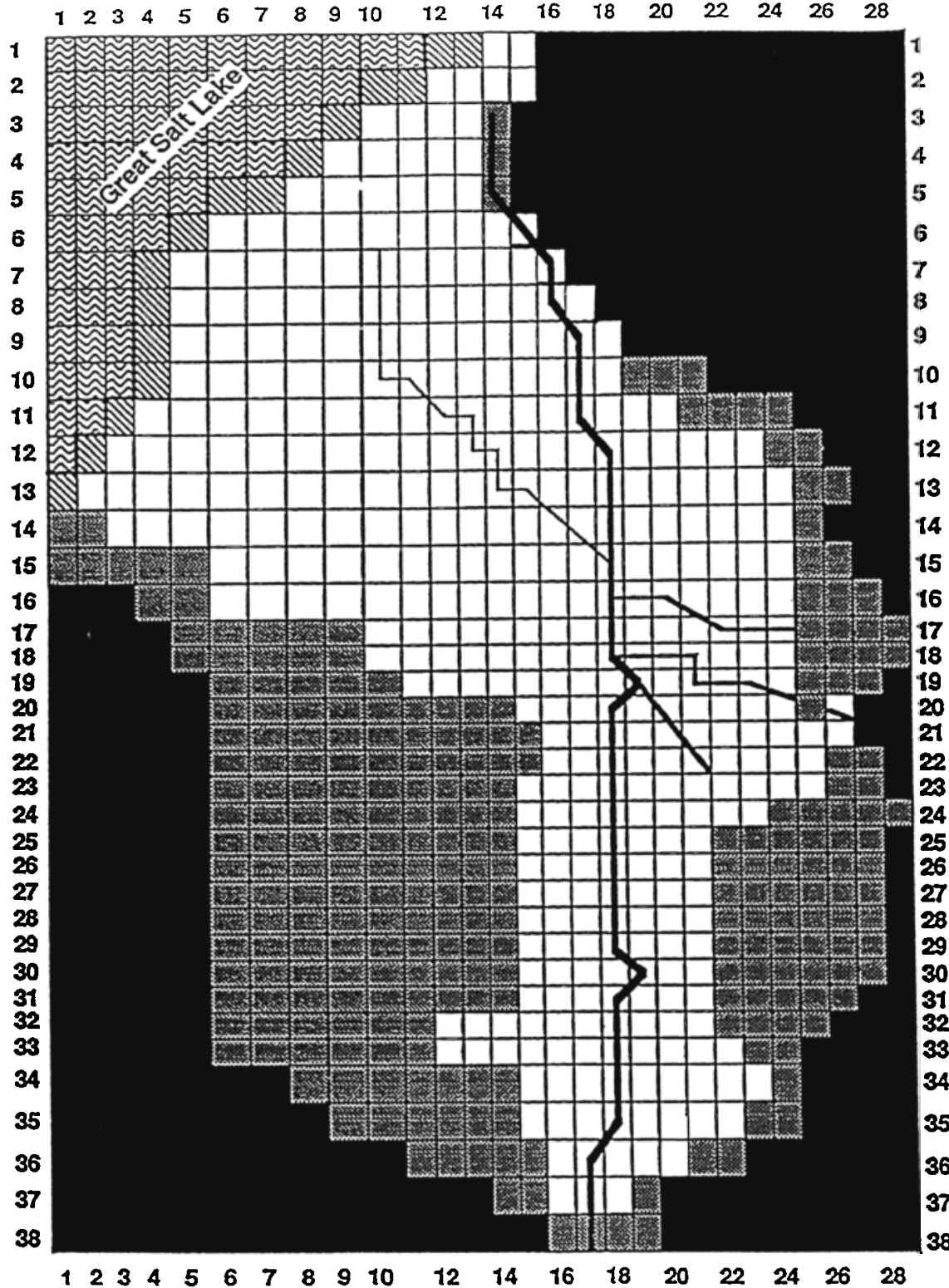

\section{Layer 1 (Upper layer)}

Legend
Constant head
cell
$\square$ Variable head
cell

Cells in study area, which do not have an upper aquifer

- Jordan River Jordan River tributary Surplus Canal

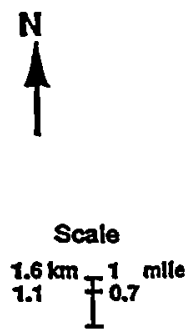

et al., 1988; Waddell et al., 1987a]. In recent years, groundwater levels declined 5 to 15 feet $(1.52$ to $4.57 \mathrm{~m})$ in the southeastern part of the valley. Declines of 40 to 60 feet $(12.19$ to $18.29 \mathrm{~m})$ are projected by the year 2000 [Waddell et al., 1987a]. A significant result will be reduced base flow from the aquifer to the Jordan River, which transects the valley from south to north.

There is also concern about water quality, especially in the southwestern part of the valley [Waddell et al., 1987b]. A large plume of dissolved solids and sulfates is moving toward wells and the Jordan River. To date, the plume underlies primarily commercial/industrial or agricultural activities and has not impacted significant residential areas [Baskin, 1990]. There are also isolated industrial plumes in the upper layer that can be hazardous if water migrates downward to the lower aquifer.

Elwell and Lall [1988] and Lall et al. [1987] developed response matrix models for the Salt Lake valley. To reduce computations, Lall et al. [1987] optimized pumping at only 46 cells where pumping is greater than $0.6 \mathrm{feet}^{3} \mathrm{~s}^{-1}(0.017$ $\mathrm{m}^{3} \mathrm{~s}^{-1}$ ) (instead of 403 current pumping cells). Their assumption that further pumping should be in wells where the discharge is already high might unnecessarily limit management options. The actual trend is to shift pumping to low-discharge cells and to encourage owners to give up or trade some of their water rights to limit pumping to areas of high water extraction. Although informative, that model ignored the effect of pumping on Jordan River flows and other fluxes between the upper aquifer and the external system.

The major groundwater-bearing formation is confined in the northern and central section of the Salt Lake valley. It is unconfined between the confined portion and the mountains. In some locations it is more than 2000 feet $(609.6 \mathrm{~m})$ thick. This formation is considered to be the second layer in the 
model. All pumping considered in the model takes place in this layer.

Between the water-bearing formation and the shallow unconfined layer is a 40 - to 100 -foot-thick (12.19-30.48 m) semiconfining bed. The thickness of the shallow unconfined aquifer ranges from a few to 50 feet $(15.24 \mathrm{~m})$. It covers a smaller area than the principal aquifer. Because of its poor water quality, it is seldom used for water supply.

The 1989 withdrawal of water from wells in Salt Lake valley was about 133,000 acre-feet $\left(164,122,000 \mathrm{~m}^{3}\right)$ or 183 feet $^{3} \mathrm{~s}^{-1}\left(5.18 \mathrm{~m}^{3} \mathrm{~s}^{-1}\right)$ [Allen, 1990]. Water levels in the principal aquifer declined in most of the Salt Lake valley in 1989. Most of the decline was recorded east of the towns of Sandy and Herriman. Currently, the only permit applications to develop groundwater that are being approved in the valley are for single-family wells in the county (i.e., away from municipal water supply). In some areas, no new groundwater development is being approved at all.

Concern about poor water quality exists mainly in the southwestern portion of the valley. A Dames and Moore [1989] report indicates that groundwater contains total dissolved solids ranging from $500 \mathrm{mg} / \mathrm{L}$ to $50,000 \mathrm{mg} / \mathrm{L}$. This is caused primarily by leachate from mining and industrial activities. The same report indicates that chloride concentrations vary from 10 to $900 \mathrm{mg} / \mathrm{L}$. The high chloride concentration is not related to the mining activities. These high concentrations resulted from industrial discharges, the use of chloride salts for roads, geothermal waters, and the leaching of the natural chloride salts from soils by irrigation.

Sulfate concentration ranges from $10 \mathrm{mg} / \mathrm{L}$ to 70,000 $\mathrm{mg} / \mathrm{L}$. The area of highest concentration is bounded by the Oquirrh Mountains in the west, the Jordan River in the east, Bingham Creek in the north, and Butterfield Creek in the south. A large sulfate plume is moving from the southwesten part of the valley (tailings area) toward the Jordan River. The main sources of sulfate are Bingham Reservoir, the mine dumps, the old and new evaporation ponds, the cemetery pond, tailings from Lark and Anaconda mines, and infiltration of irrigation waters.

There are isolated industrial plumes in the upper aquifer (Vitro mine tailings). Pesticides used in agricultural and urban areas can potentially migrate from the upper aquifer to the principal lower layer.

In summary, both water quality and water quantity management are needed in the Salt Lake valley. Water quantity problems can be caused by ignoring water quality problems. In Salt Lake valley in 1986, contamination of shallow groundwater was detected at six sites. Eleven privately owned wells and one public well were closed. Unless an appropriate groundwater management strategy is implemented (causing the evolution of a suitable potentiometric surface in both aquifers), the following problems might result: (1) A satisfactory sustainable groundwater yield will not be guaranteed, and the reliability of groundwater will be questionable for the rapidly growing population in Salt Lake valley. (2) Users of surface water from the Jordan River and its tributaries might face a severe water shortage. (3) A significant decline in the water table will make pumping more expensive and increase costs of water to purchasers. (4) Some existing water rights might not be satisfied. (5) Excessive pumping in the northern part of the valley can potentially result in saltwater intrusion from the Great Salt Lake. To prevent these problems, planners need a reliable tool for developing desirable management strategies. The model described earlier is used here to compute optimal sustainable groundwater pumping strategies, subject to specified physical and managerial constraints. Managing migration of the large sulfate plume is addressed through finite element transport constraints. Preventing downward migration of the Vitro tailings contamination is addressed by constraining heads.

\section{Model Input Data}

No optimization model can be developed without first having a calibrated simulation model. Data and discretization from the only available calibrated model of the entire valley [Waddell et al., 1987a] were utilized in this study. Included are data on bedrock recharge, precipitation, seepage from irrigation and canal streambeds, soil characteristics, and pumping cell locations. Transmissivities of the unconfined aquifer are assumed to be constant [Waddell et al., 1987a]. This assumption is valid when drawdown is relatively small compared to the saturated thickness. In all runs the constraint on drawdown is likely to enforce that previous assumption.

The study area is bounded on the north by Davis County, to the northwest by the Great Salt Lake, to the east and southeast by the Wasatch Front Mountains, to the west and southwest by the Oquirrh Mountains, and to the south by the Jordan narrows. A block-centered finite difference formulation is used with rectangular cells ranging in size from 0.7 to 1 miles $(1.12$ to $1.6 \mathrm{~km}$ ) in both rows and columns (Figure 1).

The 1086 cells include 60 river, 403 pumping, 12 general head, and $201 \mathrm{Et}$ cells. Unsteady flows from all these cells and processes are variables determined by optimization. The Jordan River, tributaries, and canals are divided into eight reaches in which stream/aquifer interflow are separately constrained. This helps avoid computing unacceptable interflows when the optimization model is applied.

Groundwater contaminant concentration is to be managed in a subsystem (Figure 1, rows 30-34, columns 6-15). Sulfate concentration changes of less public interest will occur outside that area [Dames and Moore, 1989]. The subsystem includes 48 finite difference cells. Since finite element nodes are also centers of finite difference cells, the subsystem includes 48 finite element nodes and 34 rectangular elements (Figure 2). Also from Dames and Moore [1989] are estimates of sources of sulfate and corresponding mass flux rates. Sources exist in nodes $5,8,11,12,23,26$, and 3 at rates ranging from 2.6 to 0.04 feet $^{3} \mathrm{~s}^{-1}\left(0.07\right.$ to $\left.0.001 \mathrm{~m}^{3} \mathrm{~s}^{-1}\right)$. These include recharges from rainfall, bedrock, and irrigation with concentrations of at least 100 ppm sulfate. Details are given by Gharbi [1991].

The isolated small plume (Vitro tailings area) in cell $(16,18)$ is addressed by constraining head in the upper layer to not exceed head of the lower layer, preventing the movement of water of poor quality to the principal aquifer (and ensuring that head in the considered cell is lower than that of the surrounding cells).

Dirichlet (specified head) boundaries lie to north and northeast and reflect the Great Salt Lake. Neumann conditions (specified or no flow) lie in other directions. Recharge and discharge boundaries are specified along the Jordan River, lower reaches of tributaries, and the surplus canal. Discharge through evapotranspiration occurs in the central and northern parts of the upper unconfined layer. 


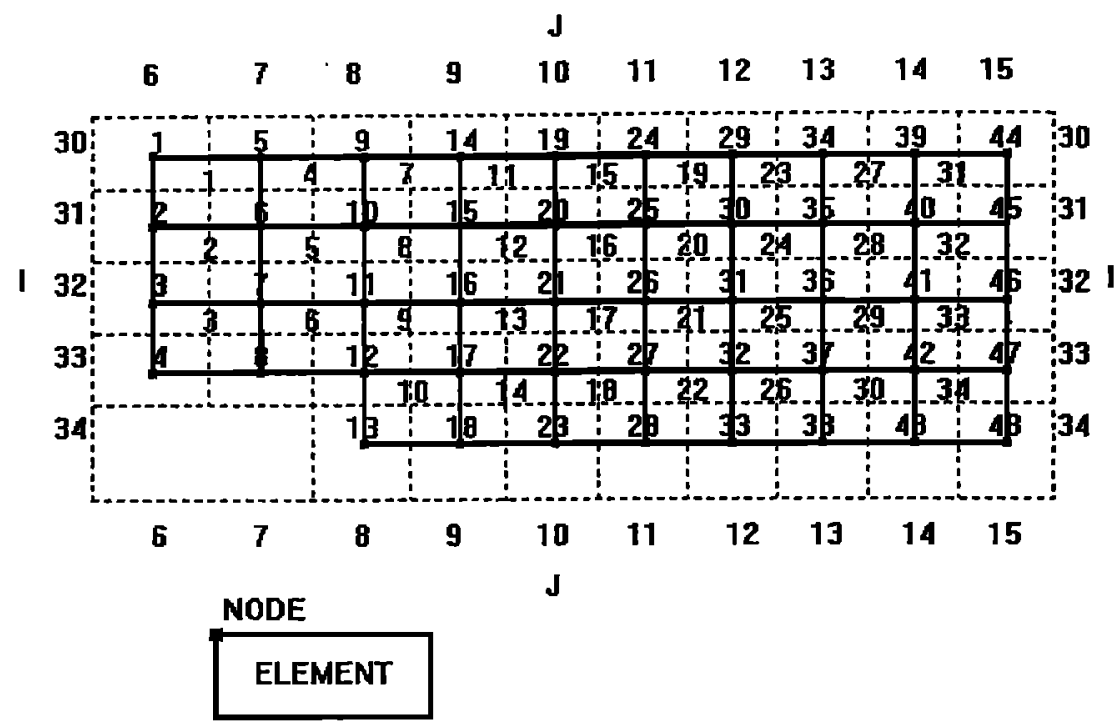

Figure 2. Groundwater contamination subsystem discretization.

Assumptions of MODFLOW, SUTRA, and the following are used: (1) The first layer is unconfined and the second is confined in some locations. (2) Flows are corrected when a second-layer cell becomes unconfined. (3) Transmissivity is unchanged within a stress period and is computed at the beginning of each cycle, using the average head for that stress period from the previous cycle. Consequently, transmissivities are known before and during a simulation or optimization cycle. (4) Transmissivities between cells are computed using the harmonic mean formulation. (5) Boundary conditions are assumed constant during the entire planning period (they could be variable if adequate data were available). (6) Pumping from all wells in a single cell is represented by a single distributed discharge value. (7) A quasi three-dimensional formulation adequately represents flow. (8) Advective-dispersive transport of the sulfate plume is conservatively estimated using a nonreactive twodimensional formulation.

\section{Scenarios}

To better manage the future, one should know the result of continuing current management (the unoptimized scenario). Comparison between the unoptimized scenario and results of different optimal scenarios is then useful to water managers.

After consultation with U.S. Geological Survey (USGS) personnel some minor modifications were made to the data of Waddell et al. [1987a]; mainly concerning constant head cell locations. Also, the USGS pumping locations and withdrawal quantities data were combined with more recent data (D. Hansen et al., unpublished data, 1990). The result totaled 158.2 feet $^{3} \mathrm{~s}^{-1}\left(4.48 \mathrm{~m}^{3} \mathrm{~s}^{-1}\right)(114,637$ acre-feet/year $1.4 \times$ $10^{8} \mathrm{~m}^{3} /$ year).

To validate USUEM, its flow simulation ability was first compared with that of MODFLOW for the same study area. When continuing current pumping for either steady state or transient conditions, both models computed essentially the same results. The greatest difference between simulated heads was less than 0.018 feet $(0.005 \mathrm{~m})$. Similarly, transport simulation of USUEM was validated by comparison with SUTRA (predicted concentrations were within 1\%).

\subsection{Unoptimized Condition Computation}

If current pumping is continued for the next 20 years, projected drawdowns in the upper layer are small. In the lower layer, drawdowns as great as 40 feet $(12.19 \mathrm{~m})$ are expected in the southwestern part of the valley (Figure 3). Simulated rates of change in storage decrease with time, showing that the system is approaching some steady state condition.

Figures $4 \mathrm{a}$ and $4 \mathrm{~b}$ show current sulfate concentrations and those projected to result during the next 20 years if current pumping continues. Twenty-five of the 48 subsystem nodes contain pumping as a decision variable. In 22 of the 48 total nodes and seven of the 25 pumping nodes, concentrations already exceed the 500-ppm health standard, although the groundwater is still being pumped and used. After 20 years, concentration will exceed the health advisory level in 17 of the 25 pumping nodes.

The increase in concentration is as great as $3127 \mathrm{ppm}$ in pumping node 34 , cell $(31,13)$. This results from sulfate migration from adjacent node 29 , cell $(31,12)$. A very high sulfate concentration is recorded in node 5 (not a pumping node) because Bingham Reservoir is a source. In some nodes, concentrations are decreasing due to elimination of the sulfate source (closure of evaporation ponds in nodes 29 and 30 cells $(30,13)$ and $(29,13)$, respectively), pumping, or dilution with higher-quality water (inflow from rainfall, bedrock, and seepage). Along most of the subsystem boundary, groundwater left the subsystem. Other than fixed bedrock recharge, groundwater entered the subsystem only in three cells (Figure 4a, row 34, columns 9-11). Here contaminant entering the subsystem was at the concentration known to exist in the source cells at the beginning of optimization. Given the slowness of flow, the resulting error seems acceptable. At worst, the concentration of the entering groundwater is being overestimated because concentrations decrease to the south. 


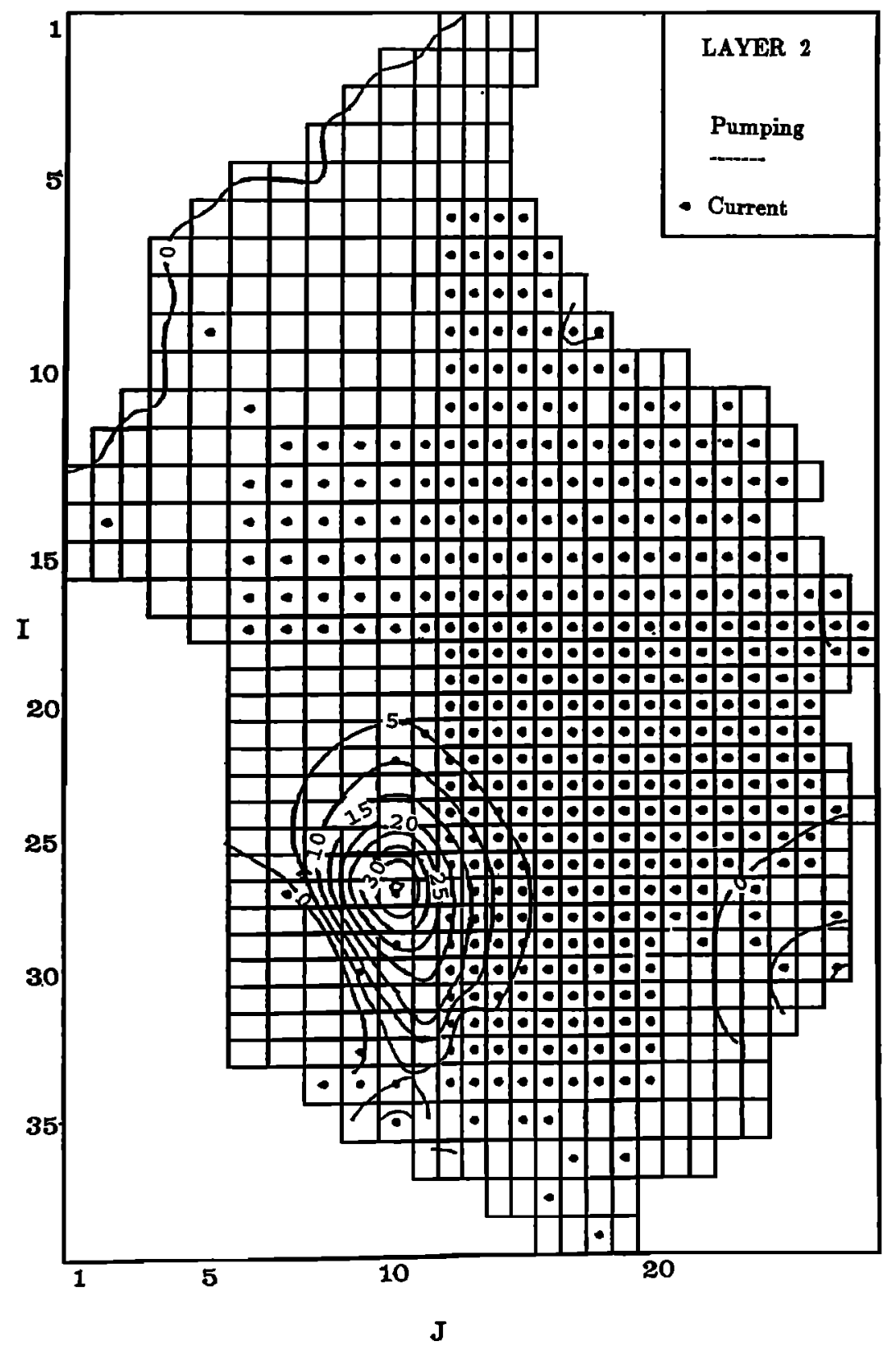

Figure 3. Drawdown contours in layer 2 after 20 years of the unoptimized scenario, in feet $(1$ foot $=$ $0.3048 \mathrm{~m})$.

The main concern is the movement of sulfate toward pumping wells and the Jordan River. Figure $4 \mathrm{~b}$ shows the 500-ppm sulfate contour moving to the east where most of the pumping is occurring. The sulfate will move about 2 miles $(3.2 \mathrm{~km})$ in the next 20 years in the eastern part of the subsystem. If current pumping is continued, sulfate concentrations will be a problem in most subsystem pumping nodes. Only the southeastern portion of the study area is expected to continue satisfying the 500-ppm standard.

\subsection{Upper and Lower Bounds Used in the Management Scenarios}

Upper and lower bounds used in scenarios A-D (described in section 7.3) and the sensitivity analysis are summarized as follows. The lower bound on pumping is $80 \%$ of current pumping. The upper bound on pumping equals current pumping for cells where there is a current moratorium preventing increased pumping and 4 times current pumping for other pumping cells.

The lower bound on variable heads in the first layer is the base of that layer. In the second layer where most of the pumping is occurring the maximum drawdown with respect to the current heads is 20 feet $(6.1 \mathrm{~m})$, suggested by $D$. Hansen (personal communication, 1990). In each constant head cell, recharge from the Great Salt Lake to the aquifer was not permitted to exceed the maximum recharge rate currently observed in any cell (not more negative than the most negative currently observed recharge).

Total recharge from the Great Salt Lake is not permitted to exceed what is currently observed, thus insuring that the 

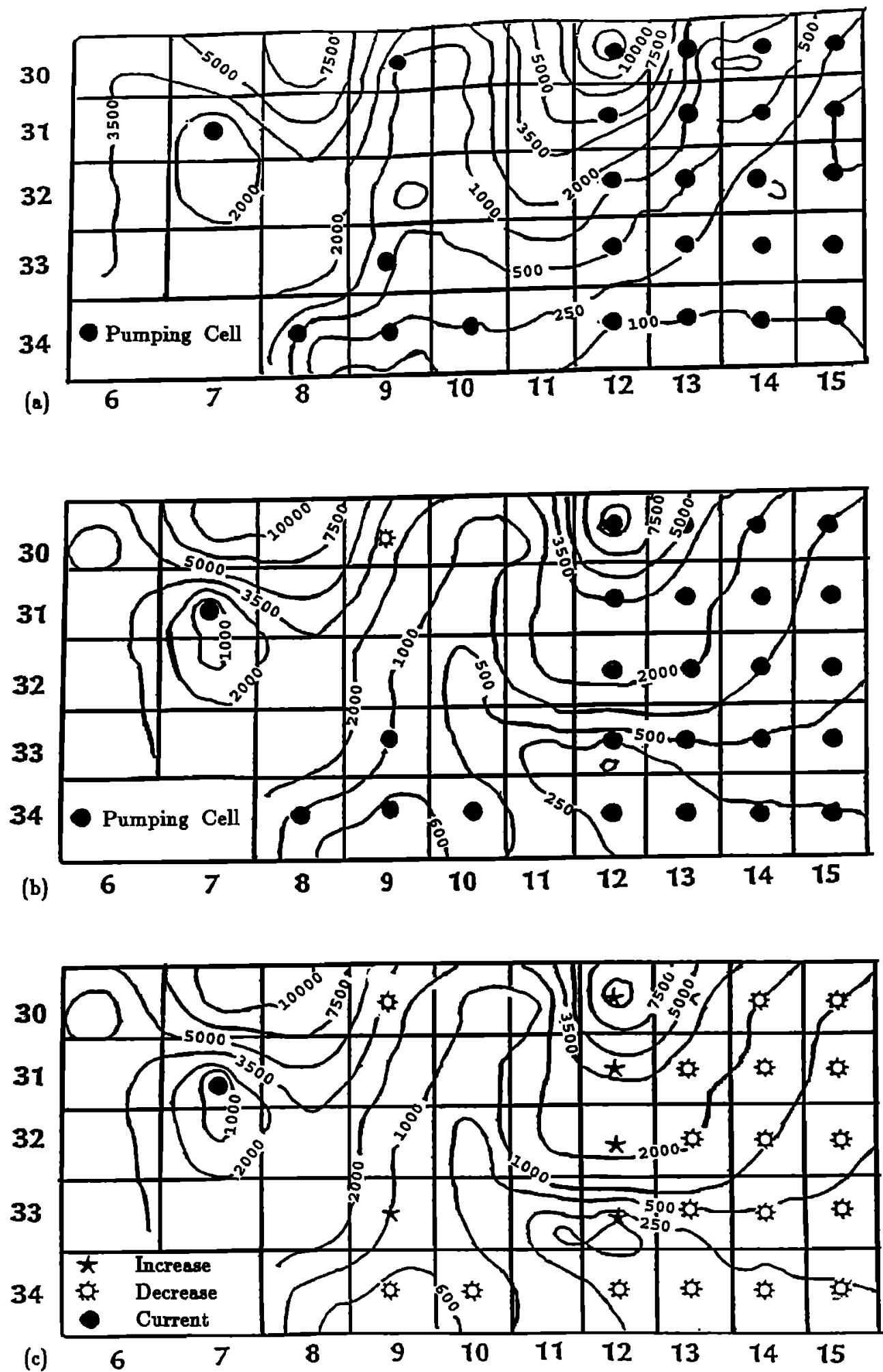

Figure 4. Sulfate concentration contours in layer 2 (a) initially, (b) after 20 years of the unoptimized scenario, and (c) after 20 years of scenario $C$, in parts per million.

increase in pumping will not result in additional influx from the lake to the aquifer. Discharge to the Great Salt Lake is unbounded. Groundwater flow to the Jordan River and its tributaries should not be less than $50 \%$ of what is currently observed.

\subsection{Scenarios Considered}

The model is used for different scenarios to demonstrate the interaction between quality and quantity management. To most economically solve the subsystem contamination 
Table 1. Summary of the Results for Tested Scenarios

\begin{tabular}{lccrrrrr}
\hline & \multicolumn{8}{c}{ Scenario } \\
\cline { 2 - 8 } \multicolumn{1}{c}{ Category } & Unoptimized & A & B & C & D & E & F \\
\hline Percent change in pumping & 0 & 27 & 27 & 25 & 15 & 16 & 18 \\
Percent change in SAI* & 0 & -22 & -20 & -19 & -9 & -12 & -12 \\
Percent change in GSLAI $\dagger$ & 0 & -37 & -35 & -34 & -77 & -80 & -67 \\
Percent of cells $\leq$ UNCON $\ddagger$ & 0 & $\cdots$ & 28 & 100 & 96 & 100 & 20 \\
Percent of cells $\leq$ STCONC $\$$ & 32 & $\cdots$ & 32 & 36 & 36 & 36 & 40 \\
\hline
\end{tabular}

*Net flow to stream from aquifer.

$\dagger$ Net flow to Great Salt Lake from aquifer.

$\ddagger$ Percentage of subsystem pumping nodes where computed concentrations do not exceed concentrations resulting from unoptimized pumping concentrations.

$\S$ Percentage of subsystem pumping nodes where computed concentrations do not exceed the standard 500-ppm concentrations.

problem, other measures beyond the scope of this study might be taken. Tested scenarios involve maximizing sustainable pumping, and in some cases, avoiding the groundwater quality deterioration resulting from management strategy implementation. An implicit goal is that any increase in pumping should not unacceptably affect the Jordan River or cause poor quality water to flow from layer 1 (the upper layer) to layer 2 (the principal aquifer) in selected sites. To attain these goals and variations thereof, the following scenarios A-F are tested:

1. Scenario $\mathbf{A}$ is to maximize steady state pumping.

2. Scenario $B$ is to maximize unsteady state pumping for a planning period of 20 years, subject to a constraint that the pumping not decrease with time and that pumping at the end of that era be sustainable.

3. Scenario $C$ is the same as scenario $B$, but including water quality restrictions. The resulting sulfate concentration should not exceed, if possible, the unoptimized concentrations (i.e., the unoptimized concentrations are used as targets). Water of poor quality should not move downward to the principal aquifer in cell $(16,18)$.

4. Scenario $D$ is the same as scenario $C$, except that 500 ppm (sulfate legal standard) is used as a target instead of the unoptimized concentrations.

5. Scenario $E$ is the same as scenario $D$, but some bounds on pumping and heads are relaxed. Lower and upper bounds on pumping are 0.4 and 8 times, respectively, the current pumping, and drawdowns up to 40 feet $(12.2 \mathrm{~m})$ are permitted.

6. Scenario $\mathrm{F}$ is the same as scenario $\mathrm{D}$, except that only the easternmost column in the subsystem has target concentrations ( $500 \mathrm{ppm})$. This slows plume movement toward the Jordan River. In addition, drawdowns up to 40 feet $(12.2 \mathrm{~m})$ are permitted.

Scenarios A and B involve only flow management and do not involve the finite element transport equations. Scenarios C-F combine both quantity and quality management. In all scenarios, decision variables are withdrawal at each pumping cell and stress period. Scenario $E$ differs from scenario $D$ in that bounds are changed somewhat to improve water quality in the pumping nodes. Scenario $F$ differs from scenario $D$ in that fewer cells have target concentrations and drawdown can be greater. The results from these scenarios and the no-future-development case of continuing current pumping will be compared in section 8 .

\section{Results and Discussion}

\subsection{Scenario A: Maximize Steady State Pumping}

The model is solved cyclically until the largest absolute difference between heads for two consecutive cycles is less than 0.1 feet $(0.03 \mathrm{~m})$ (user convergence criteria). These results reflect fluxes at optimal steady state, not necessarily those occurring at any time in the next 20 years.

The number of cycles required for convergence depends on the initial guess. However, once a feasible solution is found, only a few cycles are needed to reach the optimal solution (two to three, depending on the users' convergence criteria). Also, the time spent in each cycle is affected by the number of equations and variables. The numbers of equations and variables are 1369 and 1795 , respectively, for the partitioned model. They were 1096 and 1522, respectively, for the combined model version.

Both linear and nonlinear formulations were used alternately. Fluxes computed using the two formulations are within $2 \%$ of each other, even when different initial guesses of the solution were used in the nonlinear model. Switching from the nonlinear to the linear formulation is always problem free. When the linear formulation converged, switching to the nonlinear formulation might give an error resulting from the structure of the Jacobian matrix (a whole row of the Jacobian could be zero at an optimal solution, resulting in the singularity of the Jacobian matrix).

Under the constraints cited above, regional pumping can increase $27 \%$ from 158 feet $^{3} \mathrm{~s}^{-1}\left(4.47 \mathrm{~m}^{3} \mathrm{~s}^{-1}\right.$ ) (current pumping) to about $201 \mathrm{feet}^{3} \mathrm{~s}^{-1}\left(5.69 \mathrm{~m}^{3} \mathrm{~s}^{-1}\right)$ (Table 1). Only $31 \%$ of the 403 pumping cells increase in pumping. In 250 cells $(62 \%)$, pumping is at its lower bound, and in 113 cells $(28 \%)$, pumping is at its upper bound. Most cells where pumping increased are near the Jordan River and its tributaries. Net flow from aquifer to streams and flow to the Great Salt Lake decreased. Other fluxes remain similar to current conditions.

Drawdowns in the first layer are not restrictive and are not shown here. Figure 5 shows drawdown contours in the principal aquifer (layer 2) and identifies cells where pumping increases, decreases, or is unchanged. Groundwater flow is toward the Jordan River (Figure 5, column 18).

It is useful to determine which model version and solver are more suitable for this type of problem. Four version/ solver combinations were tested beginning with the same 


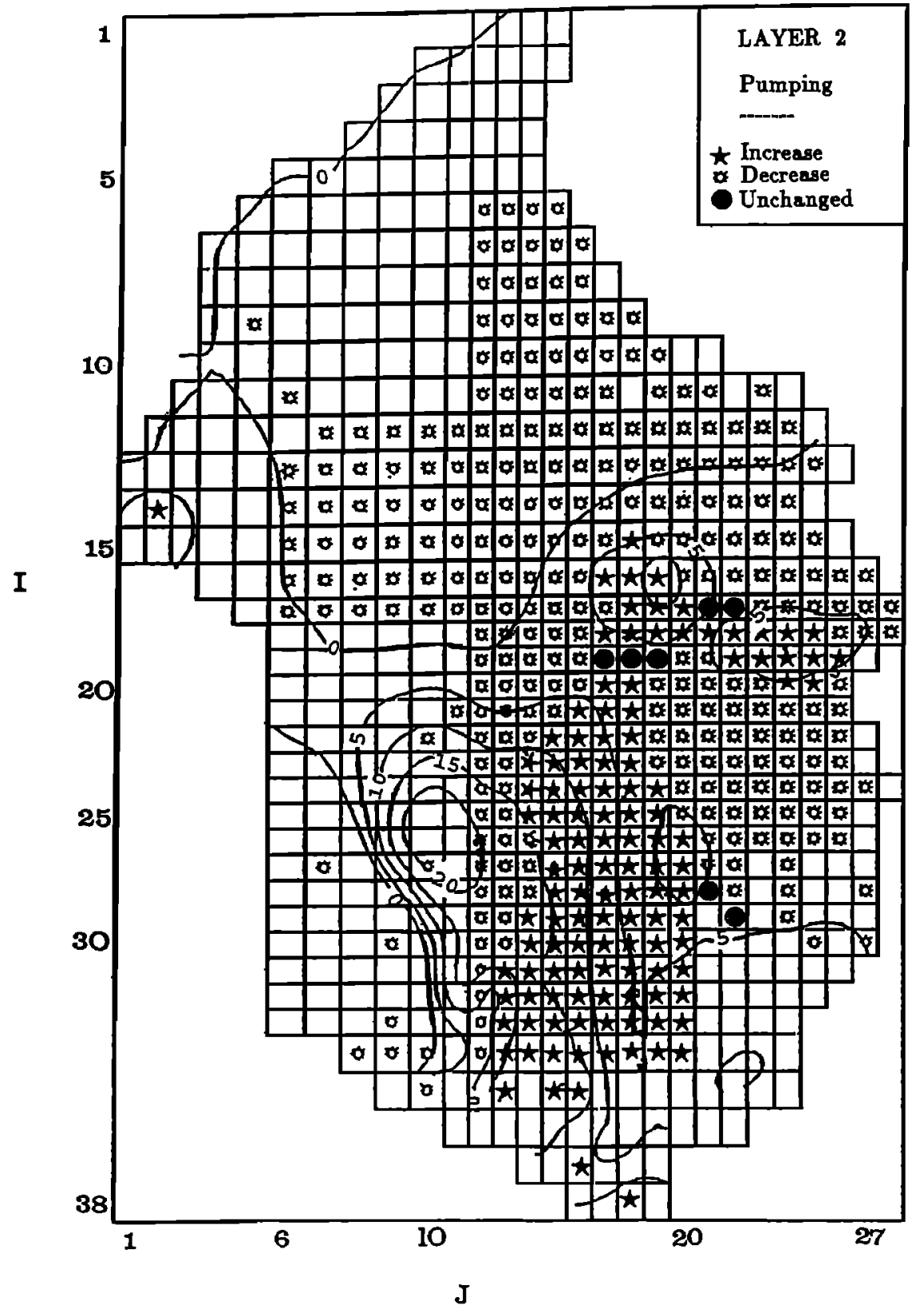

Figure 5. Drawdown contours in layer 2 after 20 years of scenario $A$, in feet $(1$ foot $=0.3048 \mathrm{~m})$.

initial guesses. System time requirement ranges from $1193 \mathrm{~s}$ for the combined LP model to $1429 \mathrm{~s}$ for the partitioned DNLP model. These are total system times on an Apollo 4500 workstation with math accelerator and 16 megabytes of random access memory (RAM), under the Sys 10.1 operating system. The combined LP formulation required only $67 \%$ as much elapsed time as the slowest formulation and seemed most suitable for this type of model.

\subsection{Scenario B: Maximize the Unsteady State Pumping Subject to a Final Sustainable Pumping After the End of Planning Period}

This scenario simulates transient groundwater flow for the 20 -year period and insures sustainability later by including the steady state flow equation. To insure monotonically increasing sustainable pumping (pumping will not have to be decreased after the 20-year planning period), equation (10) is added. The same bounds and types of equations presented previously are used for each stress period.

The number of equations and variables were 4524 and 4996, respectively, for the partitioned model. They were 4091 and 4594, respectively, for the combined model. Processing time ranged from $14,413 \mathrm{~s}$ for the combined LP model to 21,401 s for the partitioned DNLP model. Again, the combined LP model is significantly faster than other alternatives.

The sustainability constraint described above limits pumping such that those values and drawdowns are almost identical to those of scenario A. Here (and in scenario A) pumping increased in 13 out of the 25 pumping nodes within the quality subsystem. These nodes are located in the eastern side of the quality study area near the Jordan River. 
In the remaining 12 nodes, pumping decreased. Concentration increased in $72 \%$ of the pumping nodes in the quality subsystem. The highest increase in sulfate concentration resulting from the implementation of scenario $B$ is $501 \mathrm{ppm}$ after 20 years, recorded in cell $(30,12)$, node 34 . In general, the increases in concentration in the pumping nodes are not very high (only five nodes have an increase greater than 100 $\mathrm{ppm}$ ) and are smaller toward the east and the Jordan River. Sixteen nodes (68\%) will have a concentration exceeding 500 ppm. These are the same nodes having excessive concentration in the unoptimized scenario.

\subsection{Scenario C: Quantity and Quality Management With the Unoptimized Concentrations as a Target}

This scenario illustrates the trade-off between maximizing pumping and preventing concentrations from exceeding the unoptimized concentrations at control points. It uses the same flow formulation as scenario $B$, but $w c$ equals 1 rather than 0 in the objective function. The model also contains the constraints related to contamination (see equations (3)-(5)). Target concentrations are the unoptimized values in pumping nodes. This scenario answers the question, How much can we increase pumping without increasing the number of pumping nodes that will exceed the sulfate health standard? This requires using about 400 more variables and equations in scenario $C$ than in scenario $B$ and increasing processing time by about $20 \%$ once a good initial feasible solution was found. Switching between the linear and nonlinear formulations was performed. The converged optimal strategies computed by both forms were very similar. For this and subsequent scenarios, multiple optimizations were performed, each using a different initial solution guess. For a particular scenario the resulting computed strategies varied insignificantly. However, global optimality could not be assured. There are too many variables for a practical empirical proof.

Total pumping is less than in previous scenarios. Two percent of pumping is given up to achieve the quality enhancement described below. Otherwise, drawdowns and fluxes are generally similar to those computed by scenario B. Regionally, pumping increased (above current pumping) in fewer cells than in scenario $B$.

In the subsystem where quality is modeled, pumping increased in four fewer cells than in scenario B. Interestingly, the locations of cells having increased pumping are almost the opposite (cells with increased pumping in one scenario, decreased pumping in the other scenario) to what was computed by scenario B. Pumping in all cells on or near the eastern side of the subsystem decreased in scenario $C$, reducing gradients and slowing plume movement.

Target concentrations were achieved at all quality control nodes. Sulfate concentrations after 20 years are less than the unoptimized concentrations in $\mathbf{4 2}$ out of $\mathbf{4 8}$ subsystem nodes (Figure 4c). This scenario shows that the model can be used to compute a significantly enhanced sustainable pumping strategy, without causing concentrations to exceed those of the unoptimized (no future increase in pumping) scenario. Because the water quality goal was achieved, increasing the $w c$ value should not enhance goal achievement. Utilizing $w c$ values of 50 and 100 resulted in substantial reduction in pumping but negligible further reduction in concentrations. Selecting $w c$ values is a matter of trial and evaluation of results.

\subsection{Scenario D: Quantity and Quality Management Using} the Standard (500 ppm) as Target Concentrations

Time-averaged optimal pumping exceeds current pumping (Table 1) but is less than previous optimal scenarios, even though a wc of 1 is used. Pumping is at its lower bound in most cells. Pumping distribution differs from previous scenarios, being concentrated in the central eastern section of the valley. In the subsystem, pumping decreased in all pumping cells near the Jordan River and increased in four of the 25 pumping cells.

The objective to reduce concentrations to the 500-ppm health standard is not achieved in 16 out of 25 of the cells, although concentrations are less than in previous scenarios. Again, reducing pumping (mainly in the eastern side of the subsystem) and redistributing pumping slowed the plume. To improve objective attainment, some bounds should be relaxed.

In scenarios A-D, constraints and bounds that most prevented pumping from increasing are (1) lower bound on recharge from Great Salt Lake, (2) constraint on constant head, (3) lower and upper bounds on pumping, (4) lower bound on head, and (5) constraint on base flow from aquifer to river.

In regard to the above constraints the following observations can be made. Assuming that the average level will remain constant for the next 20 years, constraint 2 should not be relaxed to enhance water quality goal achievement. The large number of pumping cells at their upper and lower bounds (constraint 3) suggests that total pumping can be increased by increasing upper bounds and decreasing lower bounds. These upper and lower bounds reflect management decisions and should be chosen carefully to realistically describe the practical future. Reducing the lower bound on pumping below $80 \%$ of current pumping can be politically infeasible. Although constraint 4 is tight, reported marginals suggest that it is not as limiting as previous constraints. Also, it is important to limit drawdown within an acceptable range to avoid dewatering partially penetrating wells. In previous scenarios, constraint 5 is only tight in two or three of eight reaches. This and the value of the marginal suggest that this constraint is not very limiting. In fact, in some reaches the recharge is higher than the current recharge.

\subsection{Scenario E: Quantity and Quality Management With the Standard (500 ppm) Concentrations as a Target and Relaxed Bounds}

This scenario attempts to improve attainment of the scenario $\mathrm{D}$ objective by relaxing lower and upper bounds on current pumping and maximum drawdown. Average computed pumping is 3 feet $^{3} \mathrm{~s}^{-1}\left(0.08 \mathrm{~m}^{3} \mathrm{~s}^{-1}\right)$ greater than scenario D (Table 1). Regional pumping increases slightly and drawdown increases to 40 feet $(12.19 \mathrm{~m})$ in the east central portion of the valley. Concentrations resulting in all subsystem pumping nodes are lower than in previous scenarios. However, some nodes still exceed 500 ppm. Although lower concentrations would probably result from increasing $w c$, pumping would also be less. No other $w c$ values were tested because the main goal was regional sustainable pumping enhancement, and enhancing water quality beyond that of the unoptimized scenario would require drastically curtailing legal groundwater pumping. 
Table 2. Comparison of Sulfate Concentrations After 20 Years in the Easternmost Column of the Subsystem

\begin{tabular}{lccccccc}
\hline & & \multicolumn{7}{c}{ Sulfate Concentrations for Different Scenarios, } \\
\cline { 3 - 8 } & Cell & Unoptimized & B & C & D & E & F \\
\hline 44 & $(30,15)$ & 929 & 978 & 922 & 901 & 833 & 796 \\
45 & $(31,15)$ & 778 & 817 & 767 & 740 & 699 & 627 \\
46 & $(32,15)$ & 606 & 623 & 589 & 557 & 555 & 463 \\
47 & $(33,15)$ & 421 & 430 & 409 & 385 & 379 & 351 \\
48 & $(34,15)$ & 241 & 272 & 236 & 205 & 184 & 186 \\
$\begin{array}{l}\text { Average concentration } \\
\text { of the five nodes }\end{array}$ & & 595 & 624 & 585 & 558 & 530 & 485 \\
\hline
\end{tabular}

\subsection{Scenario F: Slowing the Movement of the Plume Toward Jordan River}

To achieve this scenario's goal, $n q$ in the objective function (equation (1)) goes from 44 to $N Q$, instead of from 1 to $N Q$. The target concentration of (5) is still $500 \mathrm{ppm}$, but the model attempts to achieve the target only in the final column of the subsystem. Reducing concentrations in these nodes will slow the movement of contaminants toward the Jordan River. The maximum allowed drawdown is 40 feet $(12.19 \mathrm{~m})$; other bounds are the same as scenarios A-D.

Average computed pumping is greater than that of scenarios $D$ and $E$ and current pumping. Drawdowns are most similar to those of scenario E. Although the water quality goal was not achieved, concentrations in the five target nodes of column 15 are lower than in any other scenario. Table 2 illustrates how average concentrations in the final column decrease as efforts to reduce concentrations increase (i.e., scenarios C-F).

\subsection{Sensitivity Analysis}

The effect of changes in aquifer parameters, bounds, and constraints on total regional pumping was evaluated (Table 3). Total pumping is somewhat sensitive to most changes but is quite sensitive to vertical river-aquifer conductances. Since most increase in pumping comes from reducing base flow and these parameters directly affect stream/aquifer interflow, one would expect these conductances to affect pumping significantly. Total pumping is also quite affected by the upper bound on pumping in individual cells. Total sustainable pumping is relatively unaffected by storage coefficient and specific yield.

The sensitivity of scenario $D$ to assumed dispersivities was also evaluated. In four sensitivity analysis runs, values used initially in scenarios C-F were multiplied by $0.0,0.5,2$, and 10 , respectively. Resulting computed pumping is relatively unaffected. The number of pumping nodes having concentrations exceeding $500 \mathrm{ppm}$ at 20 years was unchanged, although individual node concentrations did change. The regional model is not very sensitive to dispersivities for the tested scenario.

\section{Summary and Conclusions}

\subsection{Summary}

An integrated methodology for applying the embedding method to complex nonlinear groundwater management problems is tested. Via the USUEM model a combination of new linear and nonlinear model formulations is used to successfully develop optimal groundwater pumping strategies for the Salt Lake valley. This valley contains confined and unconfined aquifer layers, both large and small contaminant plumes, and declining water levels. If current pumping continues, the resulting water level declines and contaminant migration will make some wells inoperable.

There are as many possible scenarios as there are possible combinations of bounds, weights, and constraints. Scenarios

Table 3. Summary of the Sensitivity Analysis

\begin{tabular}{lcc}
\hline \multicolumn{1}{c}{ Parameter } & $\begin{array}{c}\text { Percentage Variation } \\
\text { From Values Used } \\
\text { for Scenario A or B }\end{array}$ & $\begin{array}{c}\text { Percentage Change in } \\
\text { Pumping Compared } \\
\text { With That From } \\
\text { Scenario A or B }\end{array}$ \\
\hline $\begin{array}{l}\text { Storage coefficient/specific yield* } \\
\text { Conductances } \dagger\end{array}$ & 80 to 120 & -0.1 to 1 \\
Hydraulic conductivities/transmissivities $\dagger$ & 50 to 150 & 11.5 to -36.5 \\
Lower bound on pumping $\dagger$ & 100 to 120 & 0 to 8 \\
Upper bound on pumping $\dagger$ & 0 to 75 & 13.5 to 9.5 \\
Maximum permitted drawdown $\dagger$ & 50 to $\infty$ & -7.5 to 20.5 \\
Minimum acceptable river-aquifer & 200 to 500 & 3 to 4.5 \\
interflow $\dagger$ & 40 to 160 & 4.5 to -5.5 \\
\hline
\end{tabular}

*Computed using model of scenario $A$.

†Computed using model of scenario B. 
tested above reflect what can be reasonably done to maximize sustainable pumping and control pumped concentrations. Computed optimal sustainable groundwater pumping can be $127 \%$ of current pumping. However, this assumes no special consideration is given to controlling migration of a large contaminant plume. To avoid degrading groundwater quality at pumped wells below that currently projected, the maximum sustainable pumping can be $125 \%$ of current pumping. Thus there is a minor $2 \%, 3$ feet $^{3} \mathrm{~s}^{-1}\left(0.08 \mathrm{~m}^{3} \mathrm{~s}^{-1}\right)$ trade-off between a purely volumetric goal and achieving both volumetric and quality goals.

Water quality goal achievement can be enhanced by increasing the value of its weight in the objective function. However, the natural hydraulic gradient near that plume is very steep. Without placing wells in currently nonpumping cells, using injection, or denying some existing water permits, it is not practical to prevent some well concentrations from exceeding health standards. However, plume movement toward the Jordan River can be slowed.

An interesting observation is that two-flow optimization models (neither of which considered transport) both computed the same optimal strategy, although one was much simpler than the other. A steady state model gave the same answer as a model that included (1) transient flow constraints, (2) terminal (steady state) constraints, and (3) monotonicity constraints which prevented pumping from decreasing with time. This result supports use of steady state optimization models for regional sustained groundwater yield planning.

The USUEM model contains both linear and nonlinear (discontinuous derivative) embedded finite difference flow equations and finite element solute equations. Here the temporal discretization for transport was 4 times that used for flow. Validity of the simulation ability of both linear and nonlinear forms of the model was verified by comparison with MODFLOW and SUTRA. For the same known system stresses and fluxes, USUEM computes the same system responses as those well-known simulation models.

Having both linear and nonlinear formulations is useful. It is frequently easier to develop initially optimal solutions using the nonlinear model. Subsequent optimizations proceeded more rapidly using the linear form. After repetitive optimizations both linear and nonlinear models converged to essentially the same optimal solution.

Another desirable feature is having both partitioned and combined forms of the flow equation. In the partitioned form each flux that can be described by nonsmooth function (having discontinuous derivative) is represented by a separate equation and variable. In the combined approach there is only one flow equation per cell, and only heads and pumping are variables. The partitioned form is more useful in the initial stages of optimization for identifying processes and data that cause constraint violations. The combined form is more useful later because it requires less memory and solves more rapidly.

\subsection{Conclusions}

The embedding technique can be applied successfully to optimizing long-term, reconnaissance scale planning of large-scale nonlinear groundwater problems. Here this involves embedding transient flow and transport equations, utilizing linearized and nonlinear versions of those equations, and cycling (reinitializing and repeating the optimization) until a convergence criterion is satisfied. Having both nonlinear and linear forms of the same problem is a key element of the process. The nonlinear form can be essential for developing an initial feasible or optimal solution. The linear form frequently solves and converges much more rapidly in subsequent optimizations. Both ultimately converge to nearly the same solution, lending confidence to optimality.

The modeling approach should be useful for nonlinear systems where a large proportion of the cells (1) contain pumping as a decision variable, (2) require head constraint, or (3) have fluxes described by nonsmooth functions (discontinuous derivatives). The simulation abilities of this embedding approach are useful for coarse scale management of groundwater flow and dispersed groundwater contamination. It is assumed that each cell might have many wells and that treating a cell's pumping as if it were uniformly distributed across the cell is appropriate. This approach is not a substitute for the detailed transient management capabilities of the response matrix approach.

The approach should be useful for integrating management of groundwater supply and nonpoint source pollution. The objective function emphasizes both maximizing groundwater pumping and achieving target groundwater qualities. The use of weights in the objective function permits the planner to favor one objective over the other. This makes it easy to determine trade-offs between goals.

Acknowledgments. This work was supported by the Utah Agricultural Experiment Station (approved as journal paper 4554) and the U.S. Geological Survey.

\section{References}

Ahlfeld, D. P., Two-stage ground-water remediation, J. Water Resour. Plann. Manage. Div. Am. Soc. Civ. Eng., I16(4), 517$529,1990$.

Ahlfeld, D. P., J. M. Mulvey, and G. F. Pinder, Designing optimal strategies for contaminated groundwater remediation, $A d v$. Water Resour., 9(2), 77-84, 1986.

Ahlfeld, D. P., J. M. Mulvey, G. F. Pinder, and E. F. Wood, Contaminated groundwater remediation design using simulation, optimization, and sensitivity theory, 1, Model development, $\mathrm{Wa}$ ter Resour. Res., 24(3), 431-441, $1988 \mathrm{a}$.

Ahlfeld, D. P., J. M. Mulvey, G. F. Pinder, and E. F. Wood, Contaminated groundwater remediation design using simulation, optimization, and sensitivity theory, 2, Analysis, Water Resour. Res., 24(3), 442-452, $1988 \mathrm{~b}$.

Allen, D. V., Salt Lake Valley, Ground-water conditions in Utah, spring of 1990 , edited by L. R. Herbert et al., Coop. Invest. Rep. 30, 84 pp., Utah Dep. of Nat. Resour., Salt Lake City, 1990.

Alley, W. M., Regression approximations for transport model constraint sets in combined aquifer simulation-optimization studies, Water Resour. Res., 22(4), 581-586, 1986.

Andricevic, R., and P. K. Kitanidis, Optimization of the pumping schedule in aquifer remediation under uncertainty, Water Resour. Res., 26(5), 875-885, 1990.

Atwood, D. F., and S. M. Gorelick, Hydraulic gradient control for groundwater contaminant removal, $J$. Hydrol., 76, 85-106, 1985.

Baskin, R. L., Selected factors related to the potential for contamination of the principal aquifer, Salt Lake Valley, Utah, U.S. Geol. Surv. Water Resour. Invest., 904110, 35 pp., 1990.

Bishop, A. B., T. C. Hughes, H. H. Fullerton, R. D. Hansen, M. D. Su, and I. Tsou, A color-graphics based water demand forecasting model, in Proceedings of Conference on Water-Use Data for Water Resources Management, pp. 223-232, American Water Resources Association, Bethesda, Md., 1988.

Brooke, A., D. Kendrick, and A. Meeraus, GAMS: A User's Guide, Scientific Press, San Francisco, Calif., 1988.

Chang, L. C., The application of constrained optimal control algorithms to groundwater remediation, Ph.D. dissertation, Cornell Univ., Ithaca, N. Y., 1990. 
Colarullo, S. J., M. Heidari, and T. Maddock III, Identification of an optimal groundwater management strategy in a contaminated aquifer, Water Resour. Bull., 20(5), 747-760, 1984.

Culver, T. B., and C. A. Shoemaker, Dynamic optimal control for groundwater remediation with flexible management periods, $\mathrm{Wa}$ ter Resour. Res., 28(3), 629-641, 1992.

Dames and Moore, Groundwater model for southwestern Salt Lake County, Utah, job 1375-069-31, for Kennecott Utah Copper, Salt Lake City, 1989.

Danskin, W. R., and S. M. Gorelick, A policy evaluation tool: Management of a multiaquifer system using controlled stream recharge, Water Resour. Res., 21(11), 1731-1747, 1985.

Datta, B., and R. C. Peralta, Interactive computer graphics-based multiobjective decision-making for groundwater management, Agric. Water Manage., 11, 91-116, 1986a.

Datta, B., and R. C. Peralta, Optimal modification of regional potentiometric surface design for groundwater contaminant protection, Trans. ASAE, 29(4), 1611-1623, 1986b.

Dougherty, D. E., and R. A. Marryott, Optimal groundwater management, 1, simulated annealing, Water Resour. Res., 27(10), 2493-2508, 1991.

Elwell, B. O., and U. Lall, Determination of an optimal aquifer yield, with Salt Lake County applications, J. Hydrol., 104 273-287, 1988.

Gharbi, A., Optimal groundwater quantity and quality management with application to the Salt Lake valley, Ph.D. dissertation, 196 pp., Dep. of Agric. and Irrig. Eng., Utah State Univ., Logan, 1991.

Gorelick, S. M., A review of distributed parameters groundwater management modeling methods, Water Resour. Res., 19(2), 305319, 1983.

Gorelick, S. M., C. I. Voss, P. E. Gill, W. Murray, M. A. Saunders, and $M$. H. Wright, Aquifer reclamation design: The use of contaminant transport simulation combined with nonlinear programming, Water Resour. Res., 20(4), 415-427, 1984.

Heidari, M., Application of linear system's theory and linear programming to groundwater management in Kansas, Water Resour. Bull., 18(6), 1003-1012, 1983.

Hely, A. G., R. W. Mower, and C. A. Hart, Water resources of Salt Lake County, Utah, Tech. Publ. 3l, 244 pp., Utah Dep. of Nat. Resour., Salt Lake City, 1971.

Huyakorn, P. S., B. G. Jones, and P. F. Anderson, Finite-element algorithms for simulating three-dimensional groundwater flow and solute transport in multilayer aquifer, Water Resour. Res., 22(3), 361-374, 1986.

Jones, L. C., R. Willis, and W. W. Yeh, Optimal control of nonlinear groundwater hydraulics using differential dynamic programming, Water Resour. Res., 23(11), 2097-2106, 1987.

Knapp, K. C., and E. Fienerman, The optimal steady-state in groundwater management, Water Resour. Bull., 21(6), 967-975, 1985.

Lall, U., and M. D. Santini, An optimization model for unconfined stratified aquifer systems, J. Hydrol., I1I, 145-162, 1989.

Lall, U., Y. C. Lin, B. O. Elwell, and M. D. Santini, Strategies for the conjunctive management of ground and surface waters, Rep. UTEC 87-077, 185 pp., Coll. of Eng., Univ. of Utah, Salt Lake City, 1987.

Lee, S. I., and P. K. Kitanidis, Optimal estimation and scheduling in aquifer remediation with incomplete information, Water Resour. Res., 27(9), 2203-2217, 1991.

Lefkoff, J. J., and S. M. Gorelick, Design and cost analysis of rapid aquifer restoration systems using flow simulation and quadratic programming, Ground Water, 24(6), 777-790, 1986.

Lefkoff, L. J., and S. M. Gorelick, Simulating physical processes and economic behavior in saline, irrigated agriculture: Model development, Water Resour. Res., 26(7), 1359-1369, 1990.

McDonald, M. G., and A. W. Harbaugh, A modular threedimensional finite-difference ground-water flow model, book 6, Modeling Techniques, U.S. Geol. Surv. Open File Rep., 83-875, 1988.

Molz, F. J., and L. C. Bell, Head gradient control in aquifers used for fluid storage, Water Resour. Res., 13(4), 795-798, 1977.
Murtagh, B. A., and M. A. Saunders, MINOS 5.1 User's Guide, Rep. SOL 83-20R, Dep. Oper. Res., Stanford Univ., Stanford, Calif., 1987.

Peralta, R. C., and B. Datta, Reconnaissance-level alternative optimal groundwater use strategies, J. Water Resour. Plann. Manage. Div. Am. Soc. Civ. Eng., 116(5), 676-692, 1990.

Peralta, R. C., and P. J. Killian, Optimal regional potentiometric surface design: Least cost water supply/sustained groundwater yield, Trans. ASAE, 28(4), 1098-1107, 1985.

Peralta, R. C., and P. J. Killian, Decision support for optimal regional groundwater management strategy modification, Trans. $A S A E, 30(2), 400-410,1987$.

Peraita, R. C., and R. Ward, Short-term plume containment: Multiobjective comparison, Ground Water, 29(4), 526-535, 1991.

Peralta, R. C., H. Azarmnia, and S. Takahashi, Embedding and response matrix techniques for maximizing steady-state groundwater extraction: Computational comparison, Ground Water, 29(3), 357-364, 1991.

Reichard, E. G., Hydrologic influences on the potential benefits of basin wide groundwater management, Water Resour. Res., 23(1), 77-91, 1987.

Solaimanian, J., Development of a combined quantity and quality model for optimal groundwater management, Ph.D. dissertation, 201 pp., Univ. of Ark., Fayetteville, 1989.

Tung, Y. K., and C. E. Kolterman, Some computational experience using embedding technique for ground-water management, Ground Water, 23(4), 455-464, 1985.

Voss, C. I., SUTRA: A finite element simulation model for saturated-unsaturated fluid density dependent groundwater flow with energy transport or chemically reactive single species solute transport, U.S. Geol. Surv. Water Resour. Invest., 84-4369, 409 pp., 1984.

Waddell, K. M., R. L. Seiler, M. Santini, and D. K. Solomon, Ground-water conditions in Salt Lake valley, Utah, 1969-83, and predicted effects of increased withdrawals from wells, Tech. Publ. 87, 69 pp., Utah Dep. of Nat. Resour., Salt Lake City, 1987a.

Waddell, K. M., R. L. Seiler, and D. K. Solomon, Chemical quality of ground water in Salt Lake valley, Utah, 1969-85, Tech. Publ. 89, 56 pp., Utah Dep. of Nat. Resour., Salt Lake City, 1987b.

Wagner, B. J., and S. M. Gorelick, Optimal groundwater quality management under parameter uncertainty, Water Resour. Res., 23(7), 1162-1174, 1987.

Wanakule, N., L. W. Mays, and L. S. Lasdon, Optimal management of large-scale aquifers: Methodology and applications, Water Resour. Res., 22(4), 447-465, 1986.

Willis, R., A planning model for the management of groundwater quality, Water Resour. Res., 15(6), 1305-1312, 1979.

Willis, R., and B. Finney, Optimal control of nonlinear groundwater hydraulics: Theoretical development and numerical experiments, Water Resour. Res., 21(10), 1476-1482, 1985.

Willis, R., and L. Jones, Optimization of unconfined groundwater systems: A differential dynamic programming algorithm, Geol. Soc. India, 29(1), 83-104, 1987.

Willis, R., and W. G. Yeh, Ground Water System Planning and Management, Prentice-Hall, Englewood Cliffs, N. J., 1987.

Willis, R., A. B. Finny, and D. Zhang, Water resources management in north China plain, J. Water Resour. Plann. Manage. Div. Am. Soc. Civ. Eng., 115(5), 598-615, 1989.

Yazdanian, A., and R. C. Peralta, Maintaining target groundwater levels using goal-programming: Linear and quadratic methods, Trans. ASAE, 29(4), 995-1004, 1986.

Yazicigil, H., and M. Rasheeduddin, Optimization model for groundwater management in multi-aquifer systems, $J$. Water Resour. Plann. Manage. Div. Am. Soc. Civ. Eng., 113(2), 257$275,1987$.

A. Gharbi, Esier Medjez el Bab, 4070 Medjez el Bab, Tunisia. R. C. Peralta, Department of Biological and Irrigation Engineering, Utah State University, Logan, UT 84322-4105.

(Received October 5, 1992; revised November 16, 1993; accepted November 24, 1993.) 